\title{
Using SVD Analysis of Combined Altimetry and Ocean Color Satellite Data for Assessing Basin Scale Physical-Biological Coupling in the Mediterranean Sea
}

\author{
Antoni Jordi and Gotzon Basterretxea \\ Institut Mediterrani d'Estudis Avançats, IMEDEA (UIB-CSIC) \\ Spain
}

\section{Introduction}

The ocean is a highly variable system affected by a large range of processes that spans the continuous spectra of spatial and temporal scales (Wunsch, 1996). The spatial scales of variation range from basin-wide gyres (thousands of kilometers) to turbulence (less than a meter), and the time scales from those that are climate related (decades) to short-term processes (seconds). Information on this whole range of processes is required for the comprehension of the marine system dynamics. Despite the continuous advances in technology, remote sensing is the only observing platform capable of providing continuous information on biological and physical properties over vast areas of the ocean. With some limitations, the regular and repeated coverage offered by satellites is still unachievable through in situ measurements.

Because the ocean is largely opaque over much of the usable electromagnetic spectrum, the ability of satellites to capture ocean properties is generally confined to the surface. Nevertheless, satellite-borne sensors provide us with a relatively large range of measurements such as sea surface color, sea surface height, sea surface temperature, sea surface winds, sea surface salinity, waves, and to a lesser extent, current fields. The availability, for the first time, of time series expanding for several years or decades at regional and global ocean scales has changed our perception of the ocean (Barber \& Hilting, 2000). A majority of these measurements is restricted to physical properties such as temperature, sea level or sea surface roughness and inferred variables (currents, winds, etc.). The only routinely acquired satellite measurement providing information on ocean biological processes is sea surface color. Since early measurements obtained by the Coastal Zone Color Scanner (CZCS), sea color sensors have provided quantitative information on the distribution of surface chlorophyll (CHL) concentration (an index of phytoplankton biomass) at regional to global scales and its variability in space and time (e.g., Abbott \& Zion, 1987; Antoine et al., 2005; Behrenfeld et al., 2001). This information is relevant to estimate the ocean productivity, a key factor for understanding the dynamics of pelagic foodwebs and some aspects of climate change. 
The merging of ocean color datasets with other satellite measurements providing information of ocean dynamics has potential benefits to the understanding of some aspects of the coupling between fluid driven processes and plankton dynamics. In this regard, altimetry satellite data allows the characterization of sea level anomaly (SLA), containing information on the geostrophic current fields, mesoscale eddy variability and changes in the thermocline depth (Le Traon et al., 1998; Stammer, 1997). Lehahn et al. (2007) and Leterme \& Pingree (2008) investigated the effect of the geostrophic velocity derived from satellite SLA on the redistribution of satellite CHL. Also, the impact of mesoscale eddies on the spatial patterns of CHL has been analyzed by Siegel et al. $(1999,2008)$.

Further insight into the basin-scale dynamics affecting CHL and SLA, as an indicator of changes in the thermocline depth, in the equatorial Pacific was provided by Wilson \& Adamec (2001). Correlations between CHL and SLA data using empirical orthogonal function (EOF) analysis show different responses associated with El Niño-Southern Oscillation phases. In the global ocean, direct correlations between CHL and SLA are predominately negative as lower SLA implies thermocline weakening and consequent mixing of the water column, which results in increased nutrient flux to the surface layer and phytoplankton biomass enhancement (Wilson \& Adamec, 2002). However, there are areas in all ocean basins where positive correlations suggest that $\mathrm{CHL}$ is affected by processes other than thermocline variations. For example, Uz et al. (2001) found positive correlations between satellite CHL and SLA associated with the propagation of Rossby waves. These studies exemplify how multiple satellite observations are used to understand basin-scale dynamics and their impacts on the ocean phytoplankton biomass variability. Following these works, Jordi et al. (2009) used the singular value decomposition (SVD) analysis of the cross-covariance matrix between satellite CHL and SLA to analyze the regional scale dynamics in the northwestern Mediterranean Sea. Their results highlight the role of the water mass transported by the regional circulation on the variability of the phytoplankton biomass. The SVD analysis may be superior to EOF analysis in identifying correlated spatial patterns between pairs of spatial time series (Bretherton et al., 1992).

In the Mediterranean Sea, a semi-enclosed marginal sea with limited geographical dimensions (Fig. 1), ocean color data reveals that oligotrophic conditions prevail for most of the year (D'Ortenzio et al., 2002). Biological production is mainly regulated by physical processes enhancing nutrient supply to surface layers and by allochtonous inputs from the continents and the atmosphere (Barale et al., 2008). Satellite ocean color data in the Mediterranean Sea has demonstrated dominance of the seasonal cycle in phytoplankton biomass (Bosc et al., 2004). With some regional variations, the typical temperate-latitude cycle with maximum biomass in late winter-spring and minimum during summer stratified conditions occurs throughout most of the basin (Bricaud et al., 2002). Inter-annual variations in CHL concentrations are also noticeable both at a local scale and over the whole basin, and have been related to climatic fluctuations (D'Ortenzio et al., 2003).

Complementarily, altimetry satellite data shows that the sea level variability in the Mediterranean is a complex combination of a wide range of spatial and temporal scales (Cazenave et al., 2001; Larnicol et al., 2002). Besides the marked seasonal cycle in SLA caused by the steric effect, important intra- and inter-annual signals are observed associated with permanent or transitory oceanographic structures such as frontal currents and mesoscale eddies (Jordi \& Wang, 2009; Pujol \& Larnicol, 2005). The multiple driving forces including the ocean-atmosphere interaction, the phenomenology of the deep water 
formation and water mass hydrological properties, the frontal currents and mesoscale eddies, and the topographic and coastal influence, add complexity to the physical-biological coupling in the Mediterranean Sea.

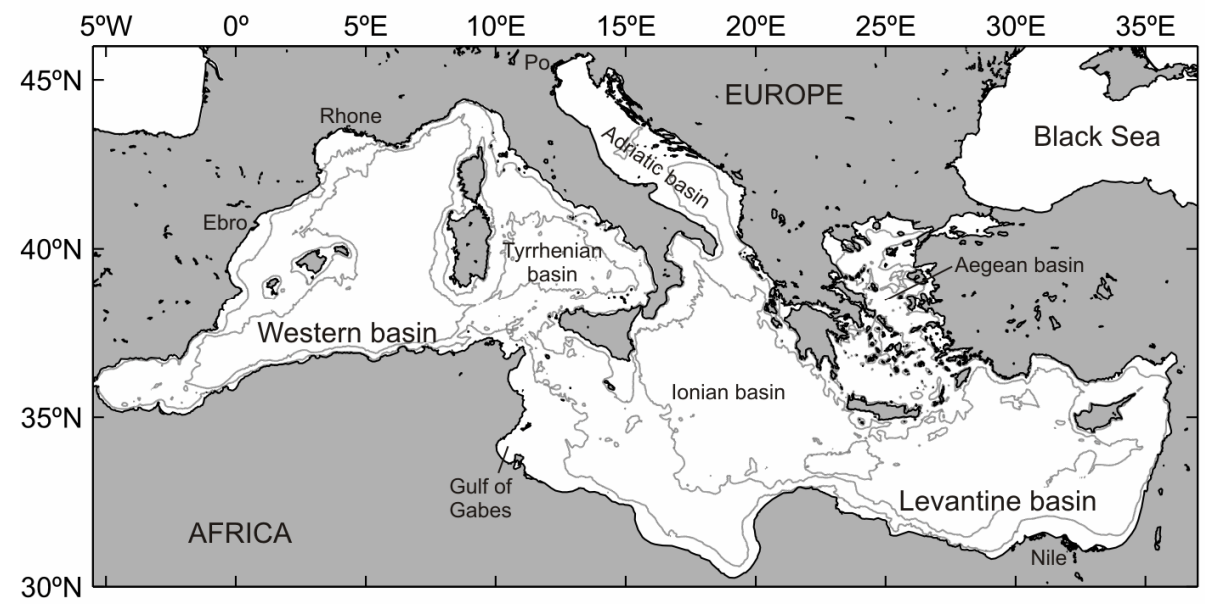

Fig. 1. Bathymetry of the Mediterranean Sea. The 200 and $2000 \mathrm{~m}$ isobaths are shown with gray lines.

In this work, we analyze the basin scale patterns of phytoplankton variability at interannual, seasonal and intra-annual scales and the associated driving forces in the Mediterranean Sea based on 12 years of concurrent ocean color and altimetry satellites data. The knowledge of the phytoplankton variability and its relation to ocean circulation is critical to understand marine ecosystem dynamics and biogeochemical cycles, with implications ranging from marine food webs to climate change. The physical mechanisms that regulate phytoplankton patterns in the Mediterranean are analogous to those in larger oceanic areas and therefore comprehension of the processes occurring therein are pertinent to the understanding of larger areas.

\section{Data and methodology}

\subsection{Altimetry satellite data}

The satellite-borne altimetry is initially designed to estimate the sea surface height (SSH) by measuring the satellite-to-surface round-trip time of a radar pulse. These measurements however include the Earth's geoid which varies by tens of meters across the ocean and is not accurately estimated ( $\mathrm{Fu}$ et al., 1994). This unknown geoid is removed from satellite observations by subtracting a long term mean of the altimeter measurements from the observations. However, this procedure removes also the mean dynamic SSH and satellite measurements refer only to SLA, which contains information on the geostrophic current fields, mesoscale eddy variability and changes in the thermocline depth (Le Traon et al., 1998; Stammer, 1997). Uncertainties on the location of the satellite on its orbit and disturbances of the radar pulse by the atmosphere introduce additional errors in the SLA 
measurement. Because of these errors, the first altimetry satellites such as Seasat or Geosat did not provide very usable and useful data. In 1993, the French Centre National d'Etudes Spatiales (CNES) and the US National Aeronautics and Space Administration (NASA) launched TOPEX/Poseidon satellite, which included a very precise positioning technique. Since then, new accurate altimetry missions were launched: ERS1/2 (in 1993), Geosat Follow-On (in 2000), Jason-1 (in 2002), TOPEX/Poseidon interleaved (in 2002), ENVISAT (in 2003) and Jason-2 (in 2008). The combination of these satellites enables high-precision altimetry and improves their spatial and temporal resolution.

It is now generally accepted that at least three altimeter missions are required to resolve the ocean mesoscale variability (Le Traon \& Dibarboure, 1999; Pascual et al., 2007). However, merging multi-satellite data requires consistent SLA data sets. Homogeneous and intercalibrated SLA fields in the Mediterranean Sea created by merging TOPEX/Poseidon, ERS1/2, Geosat Follow-On, Jason-1/2, TOPEX/Poseidon interleaved, and ENVISAT altimeter measurements, are obtained from AVISO (http://www.aviso.oceanobs.com/) for the period October 1997 to December 2009. The data set includes 7-day maps of SLA on a $0.125^{\circ} \times 0.125^{\circ}$ regular grid interpolated in time and space using a global objective analysis (Le Traon et al., 1998). The length scale of the interpolation and the e-folding time scale were set to $100 \mathrm{~km}$ and 10 days (Pujol \& Larnicol, 2005). The SLA data is re-binned in space onto a $0.25^{\circ} \times 0.25^{\circ}$ to reduce small-scale variability and in time to the satellite CHL 8-day window (see below) in order to be consistent with the temporal resolution of CHL data.

\subsection{Ocean color satellite data}

The first instrument that demonstrated the viability of satellite ocean color measurements was the US National Oceanic and Atmospheric Administration (NOAA) and the NASA CZCS Experiment aboard the Nimbus-7 satellite (Gordon et al., 1983). Although other instruments had sensed ocean color from space, their spectral bands, spatial resolution and dynamic range were optimized for land or meteorological use, whereas every parameter in CZCS was optimized for use over water to the exclusion of any other type of sensing. The CZCS ocean color data, available from 1978 to 1986, allowed a considerable progress in the knowledge of spatial and temporal variations in surface CHL in various regions of the world ocean (Antoine et al., 1996; Behrenfeld \& Falkowski, 1997; Platt \& Sathyendranath, 1988).

The CZCS provided justification for future ocean color missions such as the Japanese National Space Development Agency (NASDA) Ocean Color and Temperature Scanner (OCTS) aboard the Advanced Earth Observing Satellite (ADEOS) from 1996 to 1997 (Kishino et al., 1997) or the NASA Sea Viewing Wide Field of View Sensor (SeaWiFS) aboard the Orbital Science Corporation (OSC) Orbview-II satellite from 1997 to 2010 (Hooker \& McClain, 2000). Presently, the NASA Moderate Resolution Imaging Spectrometer (MODISA) aboard the NASA Aqua satellite (Esaias et al., 1998), and the European Space Agency (ESA) Medium Resolution Imaging Spectrometer (MERIS) aboard the ENVISAT satellite (Rast et al., 1999), both launched in 2002, provide a global monitoring of the ocean biomass. Other missions exist, with more limited coverage however, such as the Indian OCM (Chauhan et al., 2002) or the Korean OSMI (Yong et al., 1999).

To maintain the level of uncertainty of the derived products within predefined requirements, SeaWiFS and MODIS-A ocean color observations are calibrated using longterm in-situ field data (Bailey and Werdell, 2006). The calibration includes an adjustment of 
the overall response of the sensor, an atmospheric correction algorithm and the application of bio-optical algorithms (Gordon, 1997, 1998). The ocean color data used in this work consists of level 3 standard processed 8-day maps of CHL from SeaWiFS and MODIS-A on a $9 \times 9 \mathrm{~km}$ regular grid in the Mediterranean Sea obtained from NASA's Ocean Color web site (http:/ / oceancolor.gsfc.nasa.gov, see also McClain (2009)). Merging data from SeaWiFS and MODIS-A increases the coverage and reduces the uncertainties in the retrieved variables (Maritorena et al., 2010). The CHL produced by those ocean color missions are consistent over a wide range of conditions (Morel et al., 2007). We interpolate cloud-free CHL data onto the SLA grid of $0.25^{\circ} \times 0.25^{\circ}$ resolution using objective analysis with a length scale of 50 $\mathrm{km}$ and and e-folding time scale of 10 days.

Satellite derived CHL through standard algorithms in the Mediterranean Sea is affected by a calibration problem displaying a bias when compared to in situ observations (Bosc et al., 2004; Volpe et al., 2007). This difficulty is related to the specific environmental bio-optical characteristics of the Mediterranean with respect to other oceanic regions having similar ranges of CHL. However, in the present work, we use the standard calibration algorithms because we are interested in the phytoplankton variability rather than in the absolute biomass values. The satellite derived $\mathrm{CHL}$ is used as a proxy for the phytoplankton biomass in the mixed layer. Although satellite derived CHL is limited to an optical depth, a reasonable correlation exists between the depth integrated and the satellite CHL (Morel and Berthon, 1989).

\subsection{Seasonal cycles and inter- and intra-annual anomalies}

The SLA and CHL variability in the Mediterranean are dominated by the seasonal cycle (Larnicol et al., 2002; Bosc et al., 2004). As a first step, it is necessary to remove these seasonal variations because otherwise they would dominate the resultant correlations. In our case, we calculate the seasonal cycles of SLA and CHL by averaging the value for each grid point and each 8-day window. We then subtract the seasonal cycles (8-day mean values) to the original time series for each grid point to create anomalies. Finally, we apply a low- and high-pass Lanczos filter with a cut-off period of 1 year at each grid point to compute the inter- and intraannual anomalies, respectively, of SLA and CHL.

\subsection{Correlation coefficient}

The analysis of the relationships between any two satellite data sets involving large number of grid points and time series can be performed in different ways. Correlation is a simple method available when the spatial and time domains of data sets are equal. The Pearson's correlation coefficient between two time series $p(t)$ and $q(t)$ with means $\bar{p}$ and $\bar{q}$ and standard deviations $\sigma_{\mathrm{p}}$ and $\sigma_{q}$ is defined as

$$
r_{p q}=\frac{1}{(T-1) \sigma_{p} \sigma_{q}} \sum_{k=1}^{T}\left(p_{k}-\bar{p}\right)\left(q_{k}-\bar{q}\right)
$$

where $T$ is the total number of observations. We compute the Pearson's correlation coefficient for each grid point.

\subsection{Singular value decomposition (SVD) analysis of the cross-covariance}

A more sophisticated method to analyze the relationship between any two satellite data sets is the SVD analysis of the cross-covariance matrix between the two data sets with the same 
data length in time, but not necessarily the same spatial domain (Bretherton et al., 1992). The SVD analysis isolates covarying (coupled) spatial patterns of variability that tend to be linear related to one another. The SVD analysis is a generalization of empirical orthogonal function (EOF) analysis. Rather than extracting the modes that explain the greatest variance in a single data set, as in EOFs, the SVD analysis finds the covarying modes that explain as much as possible of the covariance between the two data sets.

Consider two data sets $\mathbf{s}(\mathbf{x}, t)$ and $\mathbf{c}(\mathbf{y}, t)$, consisting of SLA anomaly values at $N_{s}$ grid points and CHL anomaly values at $N_{c}$ grid points (possibly different), both for the same $T$ observation times. The data time series $\mathbf{s}(t)$ and $\mathbf{c}(t)$ at each of the grid points can be expanded in terms of a set of $N<\min \left(N_{s}, N_{c}\right)$ vectors or patterns

$$
\begin{aligned}
& \mathbf{s}(t) \cong \sum_{k=1}^{N} a_{k}(t) \mathbf{p}_{k} \\
& \mathbf{c}(t) \cong \sum_{k=1}^{N} b_{k}(t) \mathbf{q}_{k}
\end{aligned}
$$

The time series $a_{k}(t)$ and $b_{k}(t)$ are the expansion coefficients and the vectors $\mathbf{p}_{k}$ and $\mathbf{q}_{k}$ are the corresponding spatial patterns. The SVD spatial patterns are othonormal. Each pair of coefficients and patterns together (for a given $k$ ) make up a mode. The coefficients and patterns are chosen so that the first mode maximizes $\left\langle a_{1}(t) b_{1}(t)\right\rangle$, the cross-covariance of the expansion coefficients, where the brackets denote the time average over the $\mathrm{T}$ observation times. Successive pairs explain the maximum squared temporal covariance subject to orthogonality of the spatial patterns among themselves. The SVD modes are the eigensolutions of the cross-covariance matrix between the two time series.

\section{Correlations between SLA and CHL}

Ocean phytoplankton growth mainly depends on the availability of light and nutrients. Whereas light is rarely limiting in surface waters of the Mediterranean Sea (exceptions are some areas affected by river discharges), nutrient availability generally regulates phytoplankton growth. Since nutrient concentrations are higher in the deep ocean, physical processes that favor the supply nutrients from deeper layers into the surface euphotic zone will stimulate phytoplankton growth. Stratification and mixed layer depth changes are important factors regulating deep nutrient-rich waters supply to the upper ocean layer. SLA is indicative of changes in the thermocline depth because SLA primarily reflects the first baroclinic mode, which is related to the main thermocline (Stammer, 1997; Wunsch, 1996).

Figure 2 shows the correlation between the seasonal cycles of SLA and CHL at each grid point with shaded colors. Correlations that are not statistically significant at the $95 \%$ level are shaded white. Negative correlations are observed in most of the Mediterranean Sea, with highest (absolute) values in the northern part of the Western basin and lowest values between the Ionian and Levantine basins. Also, higher correlations are generally observed in oceanic water, off from the shelf. Inverse correlations in the seasonal cycles of SLA and CHL are typical of temperate regions where summer stratification inhibits the vertical flux of nutrients and winter mixing supplies nutrient-rich subsurface waters fueling phytoplankton growth. A few areas such as the Adriatic and Aegean basins, the entrance of the Gulf of 
Gabes and the Nile River delta display positive correlations. The Adriatic basin is essentially controlled by the local winter climatic conditions, rather than the nutrient inputs from deeper layers or land sources (Santoleri et al., 2003). The Gulf of Gabes signal may be an artifact produced by direct bottom reflection in areas of shallow clear waters (Jaquet et al., 1999). The other regions with positive correlations are located over the continental shelf and receive important terrestrial inputs that may override the control of seasonal thermocline oscillation on phytoplankton production in open waters.

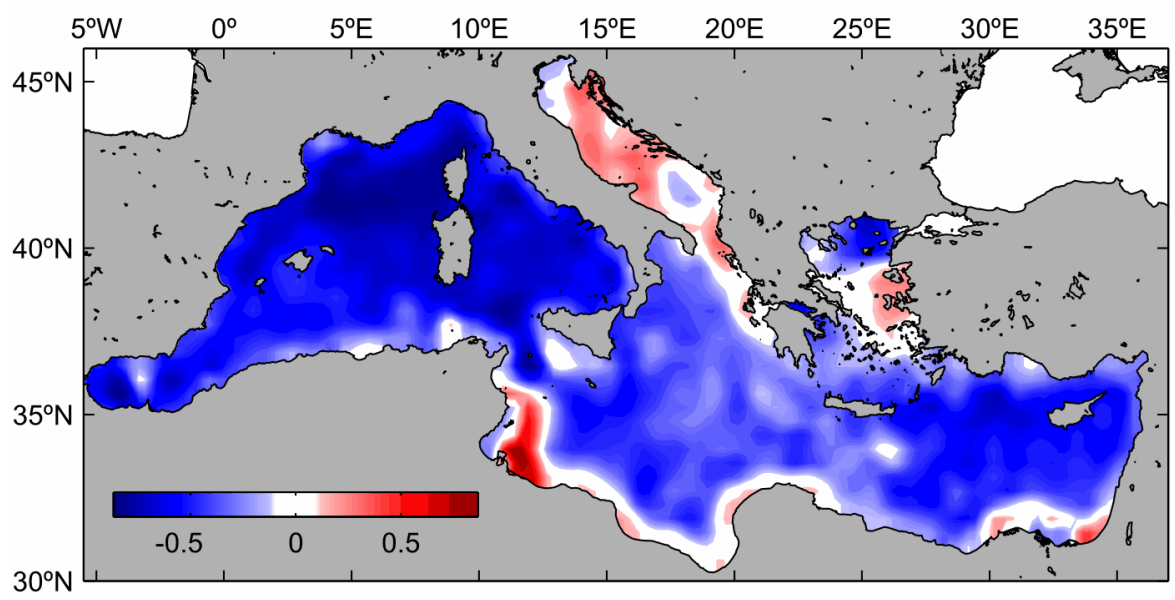

Fig. 2. Correlation coefficient between SLA and CHL seasonal cycles. The correlation in the red and blue areas is statistically significant at $95 \%$ level or more.

Although the large-scale patterns in oceanic areas observed in Figure 2 imply that SLA and related thermocline variations have key relevance on seasonal $\mathrm{CHL}$, other physical processes also modulate the biological response in the Mediterranean. The correlation between SLA and CHL anomalies at inter-annual time scale is mostly negative in oceanic areas (Figure 3), suggesting the prevalence of the coupling between SLA and CHL typical of temperate areas, as observed for the seasonal cycles. However, areas showing positive correlations increase with respect to Figure 2. Water discharges from Rhone, Ebro and Nile rivers and from the Black Sea cause these positive correlations in their influence areas. Interestingly, positive correlations are also found in the southern part of the Western basin. This area is characterized by an intense mesoscale activity produced byAlgerian eddies detached from the African coast and propagating to the north (Millot and Taupier-Letage, 2005). Vertical transfer of nutrients through eddy pumping is a dominant process modulating the biological activity in this region (Arnone and La Violette, 1986; TaupierLetage et al., 2003).

The correlation between SLA and CHL anomalies at intra-annual time scales is shown in Figure 4. Correlations are not statistically significant in most of the Mediterranean Sea. Indeed, the values of the significant correlations are notably lower than the correlations between seasonal cycles and anomalies at inter-annual time scales, suggesting that direct correlation is not adequate to analyze the relationships between SLA and CHL anomalies at intra-annual time scales. 


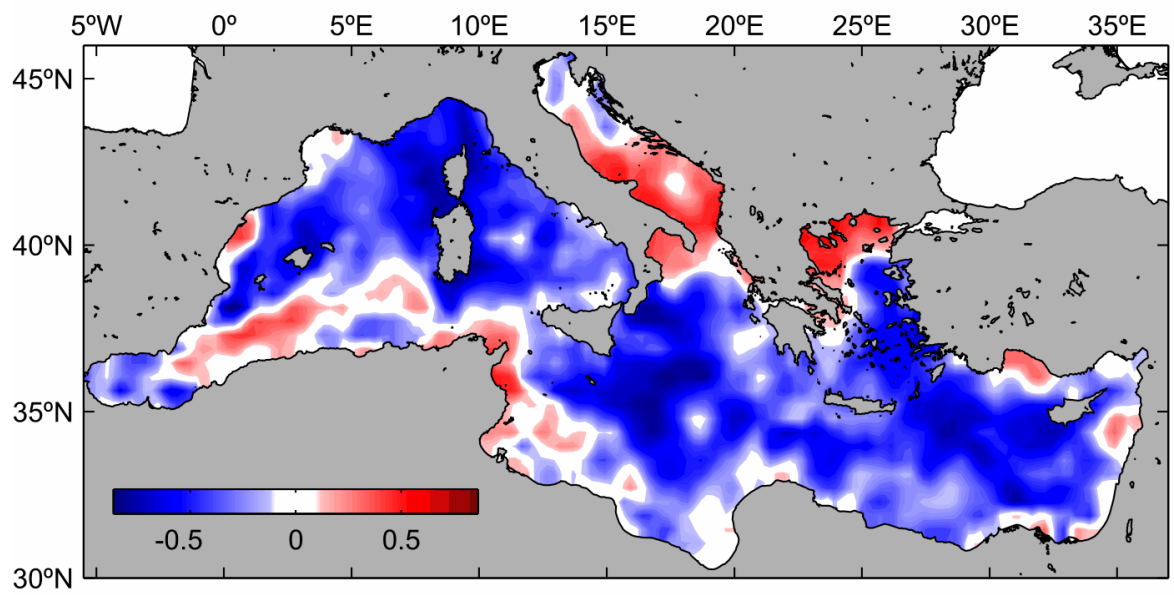

Fig. 3. Correlation coefficient between SLA and CHL anomalies at inter-annual time scales. The correlation in the red and blue areas is statistically significant at $95 \%$ level or more.

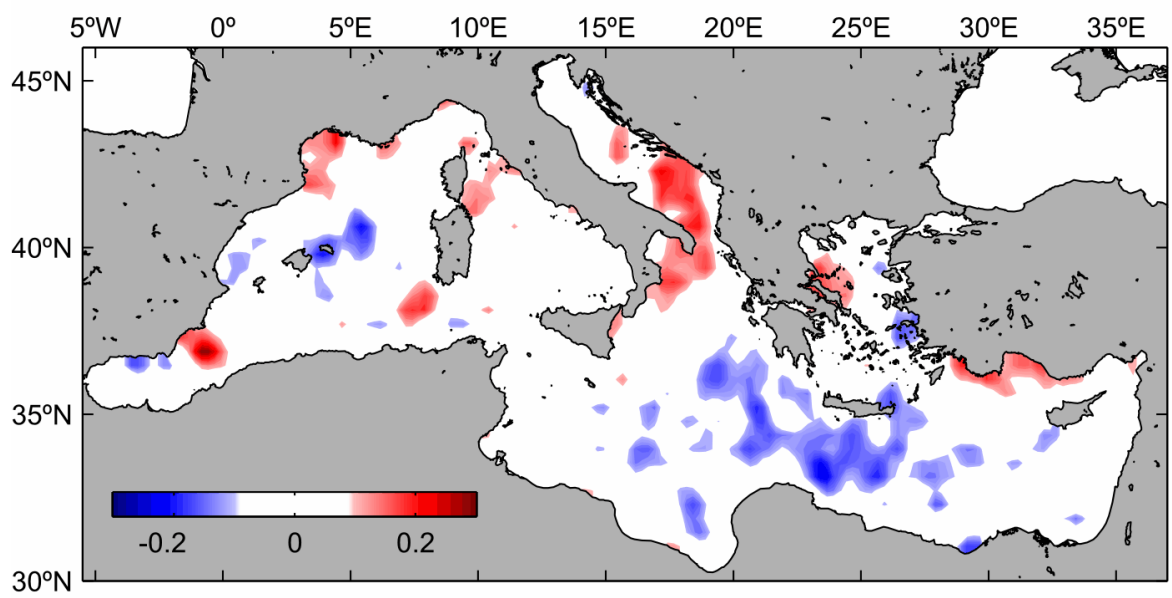

Fig. 4. Correlation coefficient between SLA and CHL anomalies at intra-annual time scales. The correlation in the red and blue areas is statistically significant at $95 \%$ level or more.

\section{SVD analysis}

\subsection{Inter-annual anomalies}

To gain further insight into the relationship between SLA and CHL anomalies at inter- and intra-annual time scales, we use SVD analysis. Figure 5 shows the spatial patterns for the first mode, which explains $41 \%$ of the covariance between the SLA and CHL inter-annual anomalies. Both patterns are scaled to represent the amplitude of SLA and CHL anomalies associated with one standard deviation of the corresponding expansion coefficients. Large 
areas of the Mediterranean Sea present the negative covariations (i.e. SLA increases and CHL decreases, or vice versa) typical of temperate areas, particularly in the Tyrrhenian, Ionian and Aegean basins. In the Levantine basin and in the southern part of the Western basin, areas with positive covariations are observed. These regions are characterized by high levels of mesoscale eddy variability (Pujol \& Larnicol, 2005). Mesoscale eddies have important biological and biogeochemical consequences, driving vertical motions of water and lifting subsurface nutrients into the surface euphotic layer (McGillicuddy et al., 1998; Oschlies \& Garçon, 1998). Positive covariations are also observed in the Adriatic basin, which is driven by the local winter climatic conditions (Santoleri et al., 2003), and in coastal areas such as Rhone, Ebro, Po and Nile river deltas, suggesting the influence of riverine inputs.
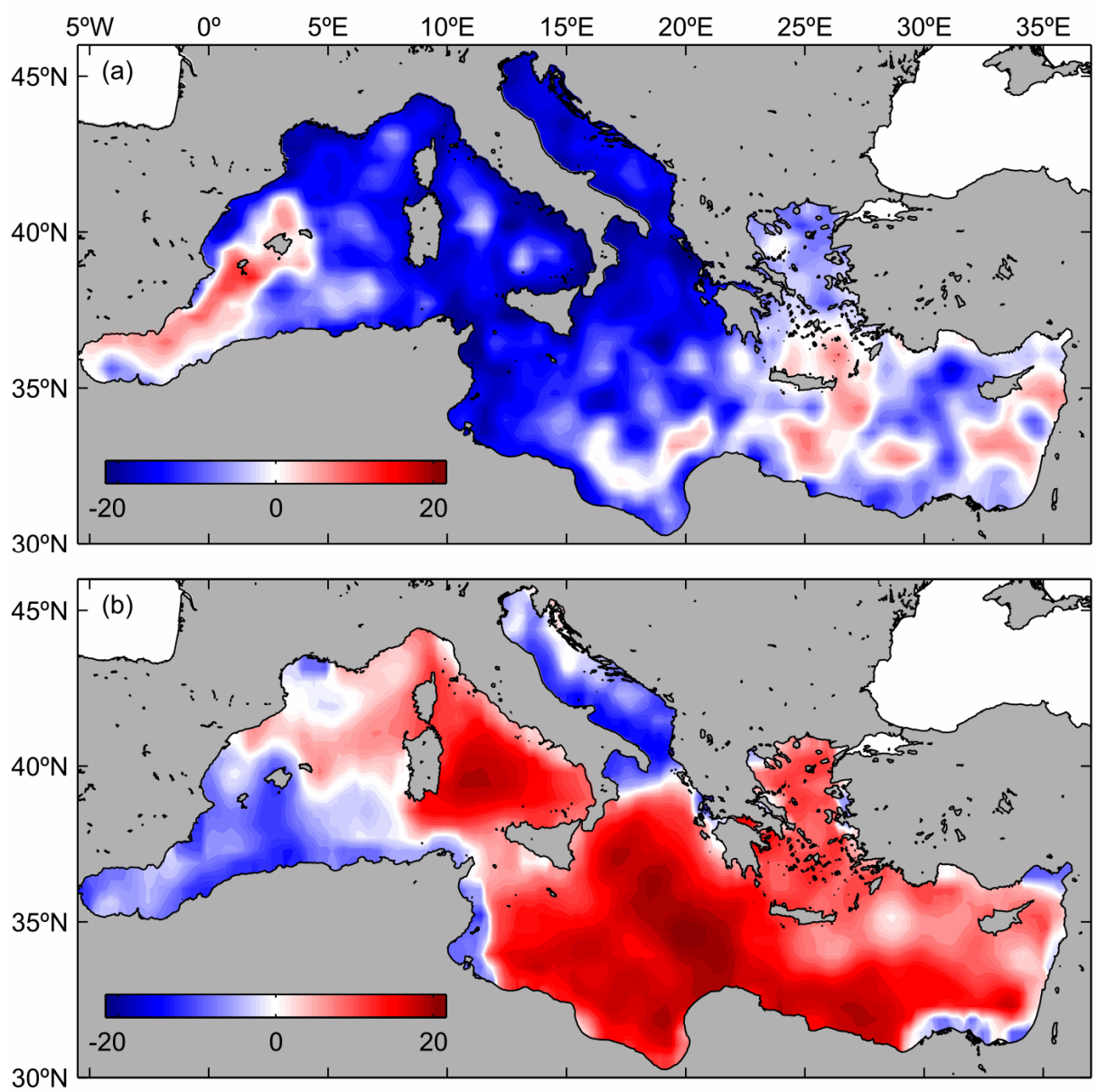

Fig. 5. First spatial patterns of (a) SLA and (b) CHL anomalies at inter-annual time scales. The patterns are scaled to represent the amplitude of SLA and CHL anomalies associated with 1 standard deviation of the first expansion coefficients. 
The spatial pattern for the second mode is shown in Figure 6, accounting for $28 \%$ of the covariance between the SLA and CHL anomalies at inter-annual time scales. The areas with negative covariations dominate in the Levantine and Aegean basins. Negative covariations are also observed in the Ionian basin, with the exception of the Gulf of Gades, although the northern and southern parts behave in opposite ways (i.e. SLA increases in the north and decreases in the south, both negatively correlated with CHL). This different behavior occurs also in the Western basin, between the eastern and western parts. The Adriatic basin and the coastal areas covary positively, as observed in the first spatial pattern.
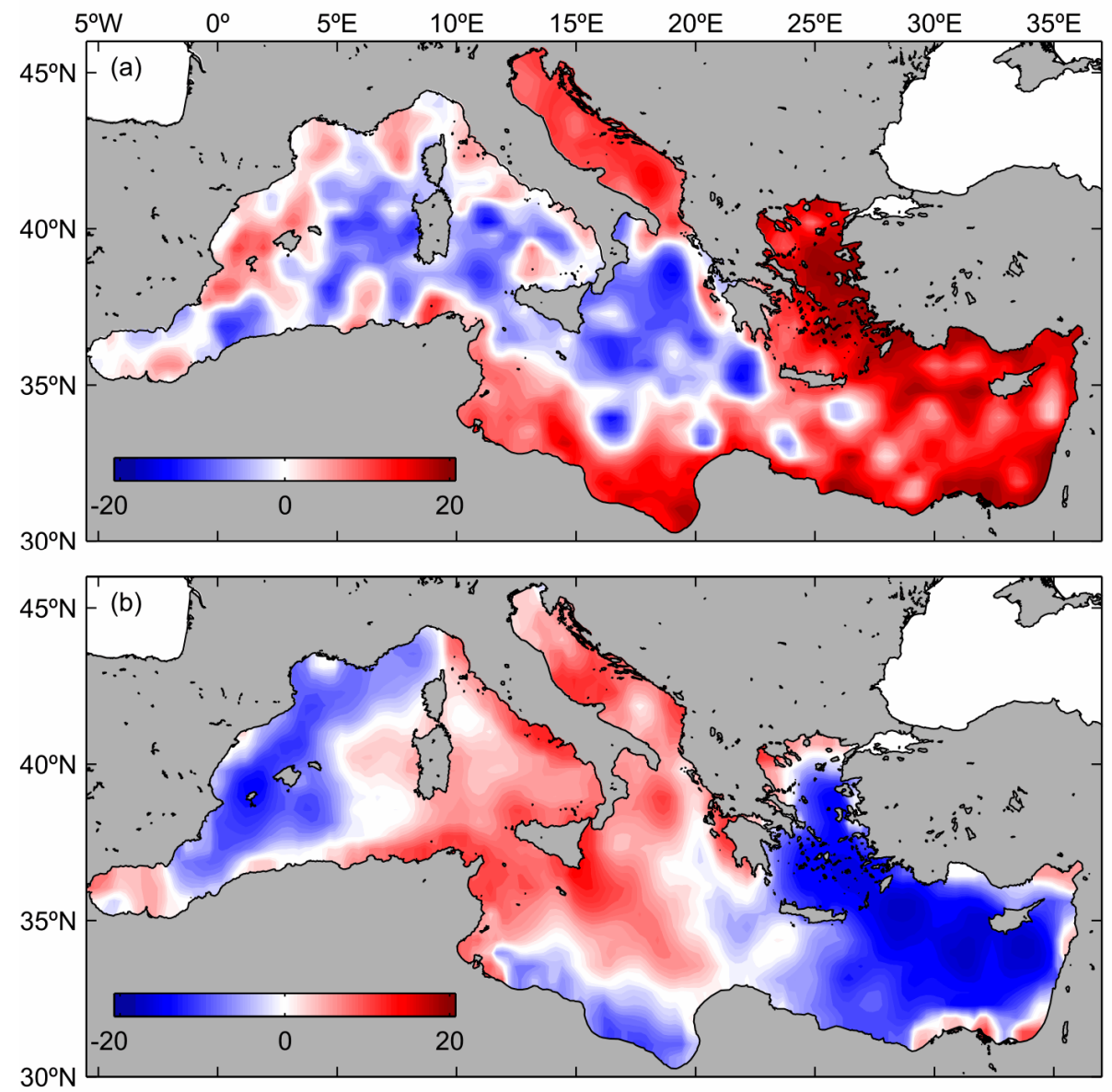

Fig. 6. Second spatial patterns of (a) SLA and (b) CHL anomalies at inter-annual time scales. The patterns are scaled to represent the amplitude of SLA and CHL anomalies associated with 1 standard deviation of the second expansion coefficients.

The time evolution of the first two modes of the SLA and CHL inter-annual anomalies is shown in Figure 7. The expansion coefficients for the first and second modes are correlated at 0.79 and 0.84 (significant at $99 \%$ level), respectively. These high values indicate that inter- 
annual variability is dominated by changes in vertical nutrient fluxes, that are regulated by the seasonal themocline dynamics. Mesosecale eddies plays also an important role, especially in the Levantine basin and the southern area of the Western basin. The Adriatic basin behaves completely different as its response is regulated by climatic conditions. Finally, riverine inputs influence the biological response in areas under the influence of major rivers.
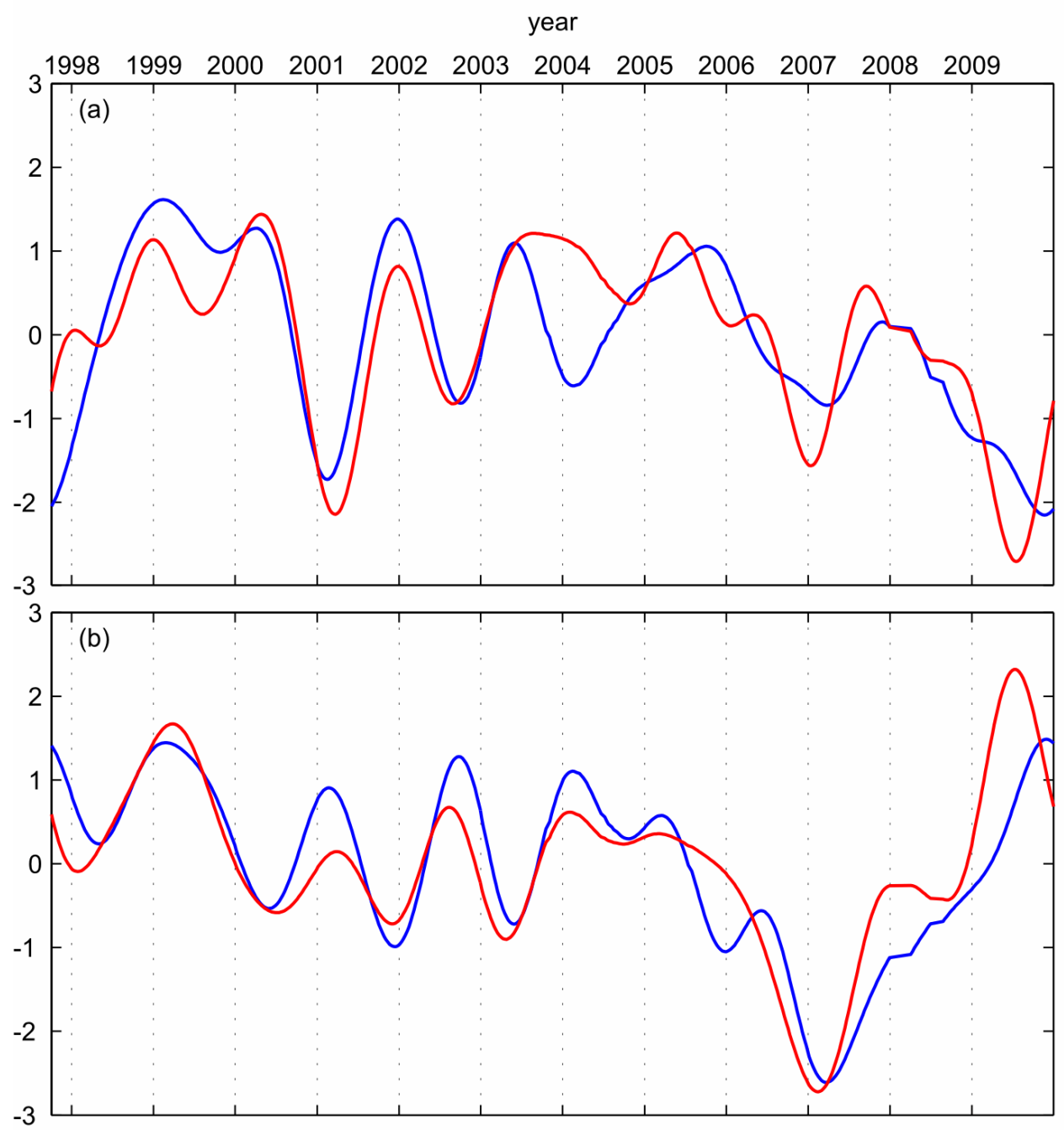

Fig. 7. Time evolution of normalized (a) first and (b) second expansions coefficients of SLA (blue line) and CHL (red line) inter-annual anomalies. 

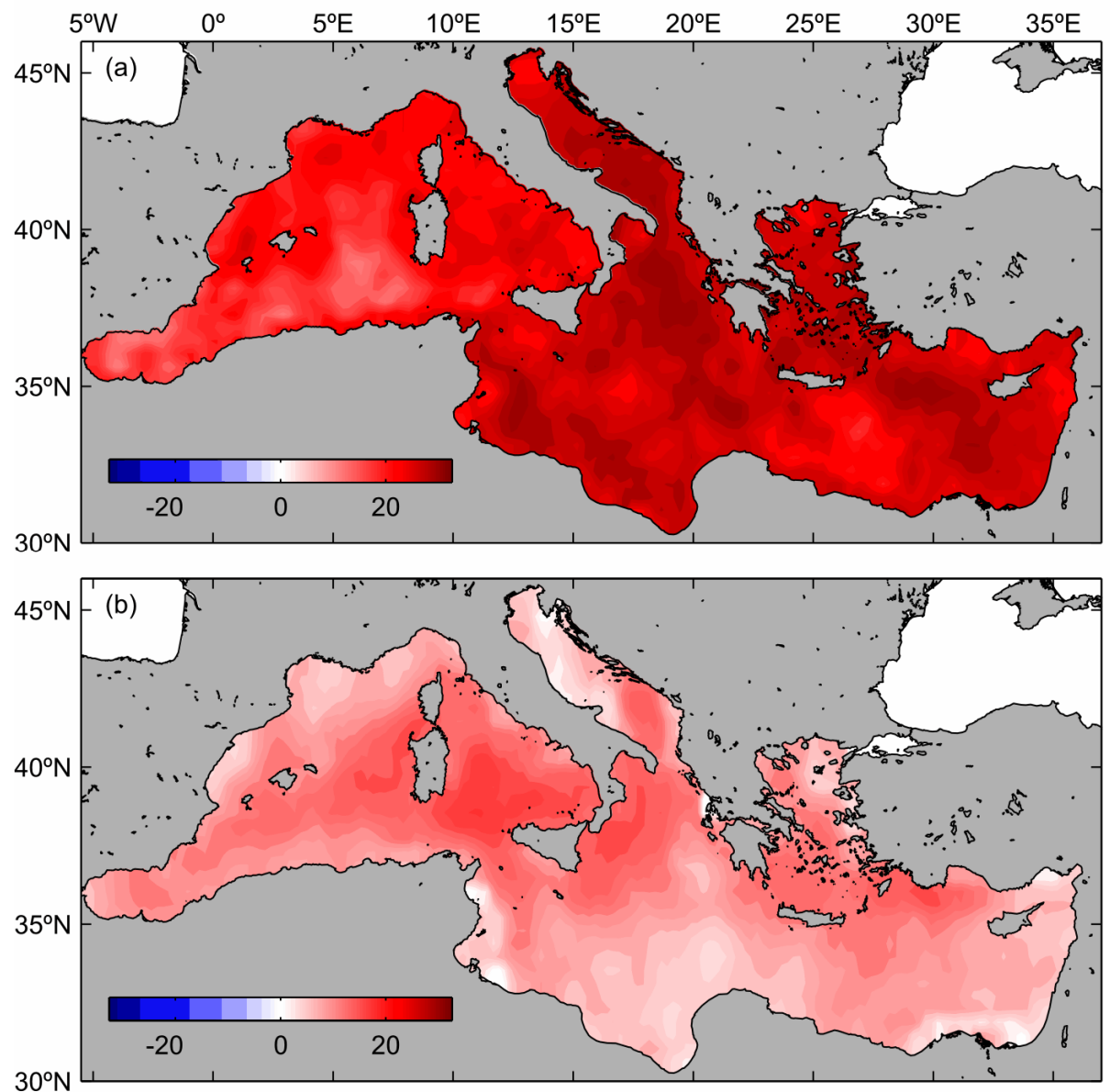

Fig. 8. First spatial patterns of (a) SLA and (b) CHL anomalies at intra-annual time scales. The patterns are scaled to represent the amplitude of SLA and CHL anomalies associated with 1 standard deviation of the first expansion coefficients.

\subsection{Intra-annual anomalies}

The spatial pattern for the first mode between the SLA and CHL intra-annual anomalies shows a significant positive covariation of SLA and CHL in the whole Mediterranean Sea. Note that variations in CHL at this time scale are markedly lower than in other modes. This behavior does not agree with that observed at inter-annual time scales, when the winter mixing enhances the upward transport of nutrients to the ocean surface. Therefore, other physical processes must be regarded in order to explain the biomass enhancement at this time scale. One candidate could be a mechanical effect indebted to oscillations in the thermocline. The modification of the thermocline depth due to the SLA variation could accumulate phytoplankton biomass close to the surface (or vice versa) and thus affect the CHL measured by the ocean color satellites without modifying the vertically-integrated 
biomass. Alternatively, the shoaling of the thermocline could extend the deeper nutrientrich layer into the euphotic surface zone, allowing phytoplankton uptake. These compression mechanisms of the ocean surface layer would be similar dynamically to the compression caused by Rossby waves (Cipollini et al. 2001). This first pattern accounts for $69 \%$ of the total covariance at intra-annual time scales, whereas the second pattern (not shown) explains less than $10 \%$ of the covariance.

Figure 9 shows the time evolution of the first mode of the SLA and CHL intra-annual anomalies. The figure only shows the period from 2002 to 2006 to facilitate the observation of short-term variability. The correlation between the first expansion coefficients for SLA and CHL intra-annual anomalies is 0.40 (significant at $99 \%$ level). Although the compression may play an important role on the enhancement of CHL observed by the satellite, the relatively modest value of correlation indicates that processes other than mechanical accumulation take place. For example, biological processes related to food web dynamics which are not coupled with the SLA should be important.

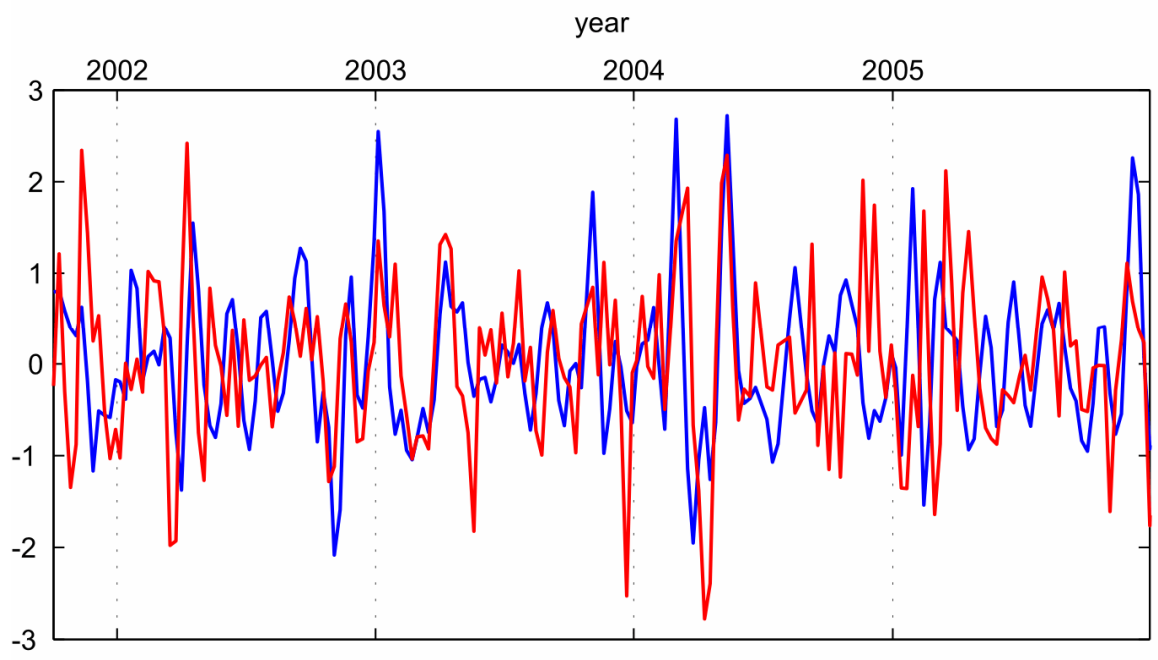

Fig. 9. Time evolution of normalized first expansions coefficients of SLA (blue line) and CHL (red line) intra-annual anomalies.

\section{Conclusion}

This study analyzes the basin scale physical-biological coupling in the Mediterranean Sea at inter-annual, seasonal and intra-annual time scales based on 12 years of concurrent satellite SLA and CHL data. Not surprisingly, the long-term (inter-annual and seasonal) variability of SLA and CHL is negatively correlated in most oceanic areas of the Mediterranean Sea. This is the typical behavior of temperate regions associated with the availability of nutrients in the mixed layer: summer stratification blocks upward entrainment of nutrients from deep layers and winter mixing brings nutrients to the surface (Cushing, 1959). In the coastal regions, particularly in those areas influenced by major rivers, the biological response is controlled by supply of nutrients of continental origin. However, other biological responses 
to the thermocline oscillations are also observed. The inter-annual SLA and CHL covary in areas dominated by mesoscale eddies, such as the Levantine basin and the southern part of the Western basin. Cyclonic eddies can enhance primary production by upwelling of nutrient rich water (McGillicuddy et al., 1998; Oschlies \& Garçon, 1998). In the intra-annual variability, the coupling between SLA and CHL is exerted through a mechanical compression mechanism, which concentrates nutrients and phytoplankton cells into the surface layer. Nevertheless, the overall influence of the mesoscale eddies and the compression mechanism in the enhancement of phytoplankton in the Mediterranean Sea deserves further study.

The SVD analysis to link SLA and CHL is a quick, easily accessible and powerful method for assessing the ocean physical-biological coupling. Our results demonstrate its strength over the direct correlation. The correlation map indicates the spatial covariability of SLA and CHL but cannot provide any details about their temporal variability. SVD analysis extracts the dominant temporal and spatial components of covariability between SLA and CHL into a series of orthogonal functions or statistical modes, and their time evolution or expansion coefficients. In addition, the SVD modes can be related to different coupling mechanism. This methodology represents a simple alternative to more sophisticated coupled physicalbiological ocean models. There are also other conceptual methods that isolate coupled modes of variability between spatial time series, such as joint EOFs or canonical correlation analysis. According to Bretherton et al. (1992), the SVD analysis is simpler and superior than these other methods in most situations involving geophysical fields.

\section{Acknowledgment}

This work was supported by EHRE (CTM2009-08270) project. A. Jordi's work was supported by a Ramón y Cajal award from the Ministerio de Ciencia e Innovación.

\section{References}

Abbott, M.R. \& Zion, P.M. (1987). Spatial and temporal variability of phytoplankton pigment off northern California during coastal ocean dynamics experiment 1 . Journal of Geophysical Research, 92 (1), 745-1,755.

Antoine, D.; Morel, A.; Gordon, H.R.; Banzon, V.F. \& Evans, R.H. (2005). Bridging ocean color observations of the 1980s and 2000s in search of long-term trends. Journal of Geophysical Research, 110, C06009, doi:10.1029/2004JC002620.

Antoine, D; Morel, A. \& André, J. M. (1995). Algal pigment distribution and primary production in the Eastern Mediterranean as derived from coastal zone color scanner observations. Journal of Geophysical Research, 100, 16193-16209.

Arnone, R.A. \& La Violette, P.E. (1986). Satellite definition of the bio-optical and thermal variation of coastal eddies associated with the African Current. Journal of Geophysical Research, 91, 2351- 2364.

Bailey, S. W. \& Werdell, P. J. (2006). A multi-sensor approach for the on-orbit validation of ocean color satellite data products. Remote Sensing of the Environment, 102, 12-23.

Barale, V.; Jaquet, J.M. \& Ndiaye, M. (2008). Algal blooming patterns and anomalies in the Mediterranean Sea as derived from the SeaWiFS data set (1998-2003). Remote Sensing of Environment, 112 (8), 3300-3313. 
Barber, R.T. \& Hilting, A.K. (2000). Achievements in biological oceanography, 50 Years of Ocean Discovery: National Science Foundation 1950-2000, pp. 11-21, National Academies Press, Washington, USA.

Behrenfeld, M.J. \& Falkowski, P.G. (1997). Photosynthetic rates derived from satellite-based chlorophyll concentration. Limnology and Oceanography, 42 (1), 1- 20.

Behrenfeld, M.J.; Randerson, J.T.; McClain, C.R.; Feldman, G.C.; Los, S.O.; Tucker, C.J.; Falkowski, P.G.; Field, C.B.; Frouin, R.; Esaias, W.E. \& others (2001). Biospheric primary production during an ENSO transition. Science, 291 (2), 594-2,597.

Bosc, E.; Bricaud, A. \& Antoine, D. (2004). Seasonal and interannual variability in algal biomass and primary production in the Mediterranean Sea, as derived from 4 years of SeaWiFS observations. Global Biogeochemical Cycles, 18 (1), doi:10.1029/2003GB002034.

Bretherton, C.S.; Smith, C. \& Wallace, J.M. (1992). An Intercomparison of Methods for Finding Coupled Patterns in Climate Data. Journal of Climate, 5 (6), 541-560.

Bricaud, A.; Bosc, E. \& Antoine, D. (2002). Algal biomass and sea surface temperature in the Mediterranean Basin - Intercomparison of data from various satellite sensors, and implications for primary production estimates. Remote Sensing of Environment, 81 (23), 163-178.

Cazenave, A.; Cabanes, C.; Dominh, K. \& Mangiarotti, S. (2001). Recent sea level change in the Mediterranean sea revealed by Topex/Poseidon satellite altimetry. Geophysical Research Letters, 28 (8), 1607-1610.

Chauhan, P.; Mohan, M.; Sarangi, R. K.; Kumari, B.; Nayak, S. \& Matondkar, S.G.P. (2002). Surface chlorophyll a estimation in the Arabian Sea using IRS-P4 Ocean Colour Monitor (OCM) satellite data. International Journal of Remote Sensing, 23, 1663-1676.

Cipollini, P.; Cromwell, D.; Challenor, P.G. \& Raffaglio, S. (2001). Rossby waves detected in global ocean colour data. Geophysical Research Letters, 28 (2), 323-326.

Cushing, D.H. (1959). The seasonal variation in oceanic production as a problem in population dynamics. ICES Journal of Marine Science, 24, 455- 464.

D'Ortenzio, F.; Marullo, S.; Ragni, M.; d'Alcala, M.R. \& Santoleri, R. (2002). Validation of empirical SeaWiFS algorithms for chlorophyll-alpha retrieval in the Mediterranean Sea - A case study for oligotrophic seas. Remote Sensing of Environment, 82 (1), 79-94.

D'Ortenzio, F.; Ragni, M.; Marullo, S. \& d'Alcala, M.R. (2003). Did biological activity in the Ionian Sea change after the Eastern Mediterranean Transient? Results from the analysis of remote sensing observations. Journal of Geophysical Research, 108 (C9), doi:10.1029/2002jc001556.

Esaias, W.E.; Abbott, M.R.; Barton, I.; Brown, O.B.; Campbell, J.W.; Carder, K.L.; Clark, D.K.; Evans, R.H.; Hoge, F.E.; Gordon, H.R.; Balch, W.M.; Letelier, R. \& Minnett, P.J. (1998). An overview of MODIS capabilities for ocean science observations. IEEE Transactions on Geoscience and Remote Sensing, 36, 1250-1265.

Fu, L.-L.; Christensen, E.; Lefebvre; M. \& Menard, Y. (1994). TOPEX/POSEIDON mission overview. Journal of Geophysical Research, 99, 24369-24382.

Gordon, H.R. (1997). Atmospheric correction of ocean color imagery in the Earth observing system era. Journal of Geophysical Research, 102, 17081-17106.

Gordon, H.R. (1998). In-orbit calibration strategy for ocean color sensors. Remote Sensing of the Environment, 63, 265- 278. 
Gordon, H.R.; Clark, D.K.; Brown, J.W.; Brown, O.B.; Evans, R.H. \& Broenkow, W.W. (1983). Phytoplankton pigment concentrations in the Middle Atlantic Bight: comparison of ship determinationos and CZCS estimates. Applied Optics, 22, 20-36

Hooker, S.B. \& McClain, C.R. (2000). The calibration and validation of SeaWiFS data. Progress in Oceanography, 45, 427-465.

Jaquet, J.M.; Tassan, S.; Barale, V. \& Sarbaji, M. (1999). Bathymetric and bottom effects on CZCS chlorophyll-like pigment estimation: data from the Kerkennah shelf (Tunisia). International Journal of Remote Sensing, 20(7), 1343-1362.

Jordi, A. \& Wang, D.-P. (2009). Mean dynamic topography and eddy kinetic energy in the Mediterranean Sea: Comparison between altimetry and a 1/16 degree ocean circulation model. Ocean Modelling, 29 (2), 137-146.

Jordi, A.; Basterretxea, G. \& Anglès, S. (2009). Influence of ocean circulation on phytoplankton biomass distribution in the Balearic Sea: Study based on Seaviewing Wide Field-of-view Sensor and altimetry satellite data. Journal of Geophysical Research, 114 (C11005), doi:10.1029/2009JC005301.

Kishino, M.; Ishizaka, J.; Saitoh, S.; Senga, Y. \& Utashima, M. (1997). Verification plan of OCTS atmospheric correction and phytoplankton pigment by moored optical buoy system. Journal of Geophysical Research, 102, 17197-17207.

Larnicol, G.; Ayoub, N. \& Le Traon, P.Y. (2002). Major changes in Mediterranean Sea level variability from 7 years of TOPEX/Poseidon and ERS-1/2 data. Journal of Marine Systems, 33, 63-89.

Le Traon, P.Y. \& Dibarboure, G. (1999). Mesoscale mapping capabilities of multiplesatellite altimeter missions. Journal of Atmospheric and Oceanic Technology, 16, 1208-1223.

Le Traon, P.Y.; Nadal, F. \& Ducet, N. (1998). An improved mapping method of multisatellite altimeter data. Journal of Atmospheric and Oceanic Technology, 15 (2), $522-534$.

Lehahn, Y.; d'Ovidio, F.; Lévy, M. \& Heifetz, E. (2007). Stirring of the northeast Atlantic spring bloom: A Lagrangian analysis based on multisatellite data. Journal of Geophysical Research, 112 (8) doi:10.1029/2006JC003927.

Leterme, S.C. \& Pingree, R.D. (2008). The Gulf Stream rings and North Atlantic eddy structures from remote sensing (Altimeter and SeaWiFS). Journal of Marine Systems, 69 (3-4) 177-190.

Maritorena, S.; d'Andon, O.H.F.; Mangin, A. \& Siegel, D.A. (2010). Merged satellite ocean color data products using a bio-optical model: Characteristics, benefits and issues. Remote Sensing of the Environment, 114, 1791-1804.

McClain, C.R. (2009). A decade of satellite ocean color observations. Annual Review of Marine Sciences, 1, 19-42.

McGillicuddy, D.J.; Robinson, A.R.; Siegel, D.A.; Jannasch, H.W.; Johnson, R.; Dickeys, T.; McNeil, J.; Michaels, A.F. \& Knap, A.H. (1998). Influence of mesoscale eddies on new production in the Sargasso Sea. Nature, 394 (6690), 263-266.

Millot, C.; Taupier-Letage, I. (2005). Additional evidence of LIW entrainment across the Algerian subbasin by mesoscale eddies and not by a permanent westward flow. Progress in Oceanography, 66(2-4), 231-250. 
Morel, A. \& Berthon, J.F. (1989). Surface pigments, algal biomass profiles, and potential production of the euphotic layer: Relationship reinvestigated in view of remotesensing applications. Limnology and Oceanography, 34(8), 1545- 1562.

Morel, A.; Huot, Y.; Gentili, B.; Werdell, P.J.; Hooker, S.B. \& Franz, B.A. (2007). Examining the consistency of products derived from various ocean color sensors in open ocean (case 1) waters in the perspective of a multisensor approach. Remote Sensing of the Environment, 111, 69-88.

Oschlies, A. \& Garçon, V. (1998). Eddy-induced enhancement of primary production in a model of the north Atlantic Ocean. Nature, 394 (6690), 266-269.

Pascual, A.; Pujol, M.I.; Larnicol, G.; Le Traon, P.Y. \& Rio, M.H. (2007). Mesoscale mapping capabilities of multi-satellite altimeter missions: First results with real data in the Mediterranean Sea. Journal of Marine Systems, 65(1-4), 190-211.

Platt, T. \& Sathyendranath, S. (1988). Oceanic primary production: estimation by remote sensing at local and regional scales. Science, 241, 1613- 1620.

Pujol, M.I. \& Larnicol, G. (2005). Mediterranean Sea eddy kinetic energy variability from 11 years of altimetric data. Journal of Marine Systems, 58 (3-4), 121-142.

Rast, M.; Bézy, J.L. \& Bruzzi, S. (1999). The ESA Medium Resolution Imaging Spectrometer MERIS - A review of the instrument and its mission. International Journal of Remote Sensing, 20, 1681-1702.

Santoleri, R.; Banzon, V.; Marullo, S.; Napolitano, E.; D'Ortenzio, F. \& Evans, R. (2003). Yearto-year variability of the phytoplankton bloom in the southern Adriatic Sea (19982000): Sea-viewing Wide Field-of-view Sensor observations and modeling study. Journal of Geophysical Research, 108(C9), doi:10.1029/2002JC001636.

Siegel, D.A.; Court, D.B.; Menzies, D.W.; Peterson, P.; Maritorena, S. \& Nelson, N.B. (2008). Satellite and in situ observations of the bio-optical signatures of two mesoscale eddies in the Sargasso Sea. Deep-Sea Research Part II, 55 (1), 218-1,230.

Siegel, D.A.; Fields, E. \& McGillicuddy, D.J. (1999). Mesoscale motions, satellite altimetry and new production in the Sargasso Sea. Journal of Geophysical Research, 104 (13), 359-13,379.

Stammer, D. (1997). Steric and wind-induced changes in TOPEX/POSEIDON large-scale sea surface topography observations. Journal of Geophysical Research, 102 (9), 2098721009.

Taupier-Letage, I.; Puillat, I.; Millot, C. \& Raimbault, P. (2003). Biological response to mesoscale eddies in the Algerian Basin. Journal of Geophysical Research, 108 (C8), doi:10.1029/1999JC000117.

Volpe, G.; Santoleri, R.; Vellucci, V.; d'Alcala, M.R.; Marullo, S. \& D'Ortenzio, F. (2007). The colour of the Mediterranean Sea: Global versus regional bio-optical algorithms evaluation and implication for satellite chlorophyll estimates. Remote Sensing of the Environment, 107(4), 625 - 638.

Wilson, C. \& Adamec, D. (2001). Correlations between surface chlorophyll and sea surface height in the tropical Pacific during the 1997-1999 El Nino-Southern Oscillation event. Journal of Geophysical Research, 106 (12), 31175-31188.

Wilson, C. \& Adamec, D. (2002). A global view of bio-physical coupling from SeaWiFS and TOPEX satellite data, 1997-2001. Geophysical Research Letters, 29 (8), 10.1029/2001GL014063. 
Wunsch, C. (1996). The Ocean Circulation Inverse Problem, Cambridge University Press, ISBN 0-521-48090-6, New York, USA.

Yong, S.-S.; Shim, H.-S.; Heo, H.-P.; Cho, Y.-M.; Oh, K.-H.; Woo, S.-H. \& Paik, H.-Y. (1999). The ground checkout test of OSMI on KOMPSAT-1. Journal of Korean Society of Remote Sensing, 15, 297-305.* 


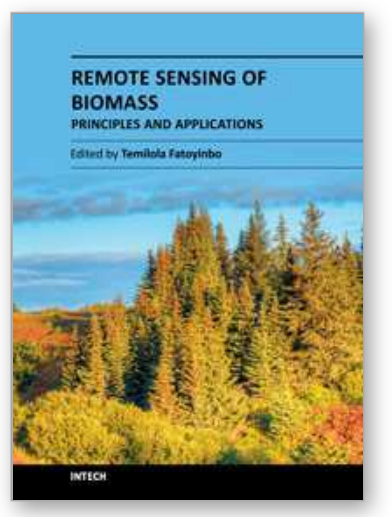

\author{
Remote Sensing of Biomass - Principles and Applications \\ Edited by Dr. Lola Fatoyinbo
}

ISBN 978-953-51-0313-4

Hard cover, 322 pages

Publisher InTech

Published online 28, March, 2012

Published in print edition March, 2012

The accurate measurement of ecosystem biomass is of great importance in scientific, resource management and energy sectors. In particular, biomass is a direct measurement of carbon storage within an ecosystem and of great importance for carbon cycle science and carbon emission mitigation. Remote Sensing is the most accurate tool for global biomass measurements because of the ability to measure large areas. Current biomass estimates are derived primarily from ground-based samples, as compiled and reported in inventories and ecosystem samples. By using remote sensing technologies, we are able to scale up the sample values and supply wall to wall mapping of biomass. Three separate remote sensing technologies are available today to measure ecosystem biomass: passive optical, radar, and lidar. There are many measurement methodologies that range from the application driven to the most technologically cutting-edge. The goal of this book is to address the newest developments in biomass measurements, sensor development, field measurements and modeling. The chapters in this book are separated into five main sections.

\title{
How to reference
}

In order to correctly reference this scholarly work, feel free to copy and paste the following:

Antoni Jordi and Gotzon Basterretxea (2012). Using SVD Analysis of Combined Altimetry and Ocean Color Satellite Data for Assessing Basin Scale Physical-Biological Coupling in the Mediterranean Sea, Remote Sensing of Biomass - Principles and Applications, Dr. Lola Fatoyinbo (Ed.), ISBN: 978-953-51-0313-4, InTech, Available from: http://www.intechopen.com/books/remote-sensing-of-biomass-principles-andapplications/using-svd-analysis-of-combined-altimetry-and-ocean-color-satellite-data-for-assessing-basinscale-ph

\section{INTECH}

open science | open minds

\section{InTech Europe}

University Campus STeP Ri

Slavka Krautzeka 83/A

51000 Rijeka, Croatia

Phone: +385 (51) 770447

Fax: +385 (51) 686166

www.intechopen.com

\author{
InTech China \\ Unit 405, Office Block, Hotel Equatorial Shanghai \\ No.65, Yan An Road (West), Shanghai, 200040, China \\ 中国上海市延安西路65号上海国际贵都大饭店办公楼 405 单元 \\ Phone: +86-21-62489820 \\ Fax: +86-21-62489821
}


(C) 2012 The Author(s). Licensee IntechOpen. This is an open access article distributed under the terms of the Creative Commons Attribution 3.0 License, which permits unrestricted use, distribution, and reproduction in any medium, provided the original work is properly cited. 